\title{
Evidentiality, Epistemic Modality, and Epistemic Status
}

\author{
Rezeda Dilshatovna Shakirova (Corresponding author) \\ Naberezhnye Chelny State Pedagogical University, 28, Nizametdinov Street, Naberezhnye Chelny, the Republic of Tatarstan, 423806, Russia \\ E-mail: shakirova-rezeda@inbox.ru \\ Guzel Abelkhasanovna Sadrieva \\ Naberezhnye Chelny State Pedagogical University, 28, Nizametdinov Street, Naberezhnye Chelny, the Republic of Tatarstan, 423806, Russia \\ Adelina Renatovna Safina \\ Naberezhnye Chelny State Pedagogical University, 28, Nizametdinov Street, Naberezhnye Chelny, the Republic of Tatarstan, 423806, Russia \\ Inga Gennadyevna Almikaeva \\ Naberezhnye Chelny State Pedagogical University, 28, Nizametdinov Street, Naberezhnye Chelny, the Republic of Tatarstan, 423806, Russia
}

Alsu Flerovna Galimullina

Naberezhnye Chelny State Pedagogical University, 28, Nizametdinov Street, Naberezhnye Chelny, the Republic of Tatarstan, 423806, Russia

Received: 23-03-2016

Published: 01-09-2016
Accepted: 02-06-2016

doi:10.7575/aiac.ijalel.v.5n.5p.32
Advance Access Published: July 2016

URL: http://dx.doi.org/10.7575/aiac.ijalel.v.5n.5p.32

\begin{abstract}
The article discusses the interaction of evidentiality categories, typical of many Turkic, Finno-Ugric, Samoyed, certain Slavic, and other languages with the categories of epistemic modality, which is widely represented particularly in Germanic languages. The methodological framework of this study consists of the general philosophic, general scientific and private levels. The general philosophic methodology is based on the analytic philosophy, under the linguistic trend of which the language study was carried out to solve philosophic problems. The general scientific methodological bases of the study are related to the principle of identifying similarities and differences of the categories analyzed and the systematicity of description, whereas the descriptive method and techniques thereof are used primarily as the privatelinguistic methods. In contrast to evidentiality, indicating the source of information, the epistemic modality marks different level of the information reliability. In the modern German language, the categories studied have a zone of intersection in terms of community within the means of expression, to which modal words and modal verbs as well as the verb scheinen can be primarily related. However, in the modern German language, there is no question of the category of evidentiality in the plane, within which it is currently being studied basing on the material of those languages, to the fragment of the grammatical system of which it is primarily inherent. As a rule, the semantics of evidentiality in these languages provides no information on the degree of reliability of the source of knowledge. To overcome the contradiction of such nature, this work suggests paying attention to the category of epistemic status of an utterance, the semantic structure of which is wider than evidentiality and epistemic modality and includes the level of reliability of the source of knowledge along with the designation thereof. In today's German language, there are units functioning that mark simultaneously both parameters of the situation, on which an utterance is based.
\end{abstract}

Keywords: evidentiality, epistemic modality, epistemic status, German language, degree of reliability, source of information.

\section{Introduction}

In recent decades, the researchers pay more and more attention to the fact that the problem of opinion and knowledge, having a long history of studies in philosophy and logic, becomes urgent in linguistics as well. Anna Zaliznyak (Zaliznyak, 2006) notes, for example, the growth of scholarly attention to this problem. I.B. Shatunovskii (Shatunovskii, 1996) argues that the problem of opinion, knowledge and belief relates less to the philosophic and ontological issue than to the linguistic one (at least by $90 \%$ ).

An increasing interest of linguistics in the problem of opinion and knowledge, which occupies a central place in the theory of cognition, is associated with the change of scientific paradigm (Kuhn, 1975) in linguistics. We are talking about the formation and the intensive development of a new, anthropocentric, scientific paradigm in linguistics, which brings into focus a native speaker, whereas the factor of a human in language becomes crucial therefor. Cognitive linguistics is one of the main trends emerging within this paradigm. It studies the mental processes related to the cognition of reality. This article aims to identify the common ground of such concepts as evidentiality, epistemic modality and epistemic status of an utterance that are of direct relevance to the language as a mental phenomenon. 
The term "evidentiality" is widespread in Russian linguistics due to the work by R.O. Jacobson "Shifters, verbal categories and the Russian verb" (1972). Following his ideas, the quality of being attested is a verbal category, which takes into account a reported fact, a fact of message, and the transmissibility of a message fact, in other words, an indication of the source of information on a reported fact. According to others, the evidentiality includes the values of an explicit marking of the speaker's source of information regarding the situation it notifies (Kozintseva, 2000).

Speaking of epistemic modality, it should be recognized that some scholars interpret it as a category associated with the degree of probability of the information reported. The supporters of this approach include V.S. Khrakovsky (2007), who defines the epistemic modality as the speaker's assessment of the degree of probability of the fact given.

Regarding the term "epistemic status", we should note that its introduction into the scientific usage associates with the name of J. Lyons (2003), who uses it for marking a subjective qualification of the speaker's attitude to the verity of a proposition.

The discussion on the correct way of using the expression "I know" launched by the representatives of analytical philosophy, in particular by G.E. Moore (1959), L. Wittgenstein (1969-1975), and N. Malcolm (1977), contributed to the identification of statements, with which this expression cannot be used due to the redundancy of the information underlying these statements. M.A. Dmitrovsky (1988), E.S. Yakovleva (1994), and others subsequently summarized such statements. Thus, studying the model of space, time and perception allowed E.S. Yakovleva (1994) to reveal that, depending on the nature and degree of the subject matter of speech awareness, a speaker can impart expression with an objective or subjective epistemic characteristic.

\section{Method}

The methodological framework of this study includes three levels: general philosophic, general scientific, and private. Analytic philosophy acts as a general philosophic methodology, within the framework of the linguistic trend of which the issue of reliability, and namely of the reliability of knowledge, was widely discussed. The general scientific methodological basis of the study are backed by the principle of identifying similarities and differences of the categories analyzed and the systematicity of the material description. With regard to the private-linguistic methods, the present study was carried out primarily within the framework of the descriptive method and the techniques or devices thereof, the purpose of which is to establish the facts and phenomena of one language, in this case of the modern German language. The descriptive method devices may include observation, generalization, interpretation, and classification. We performed observation, the task of which is to describe the features of the language units functioning, from the standpoint of applying the analyzed means in a particular communicative context using the resource of a literary text. Therefore, we can talk also about the use of the contextual analysis technique. Moreover, during the collection and analysis of the illustrative material, we used the method of continuous sampling to obtain valid and reliable results. The interpretation of the obtained language units functioning results, in this case of the modal words, modal verbs and conjunctive of indirect speech, allowed us to treat them in a new light and to allocate the category of epistemic status by means of generalization. We also applied the descriptive method to systematically describe and discuss the theoretical material. In studying the plan of the epistemic status category expression, in some cases a method of componentsemantic analysis was used.

\section{Results}

In linguistic literature, the question about the correlation of evidentiality and epistemic modality categories is raised, during the discussion of which researchers fail to concur with each other. Due to the fact that the reference to the speaker's source of knowledge does not provide information on the level of its reliability, N.A. Kozintseva (2000) suggested considering them as separate categories. S.I. Burkova (2004) adheres to a similar opinion, which denies the affiliation of evidentiality in the Nenets language to epistemic modality. From the author's point of view, they correlate only to one of the situation formats, expressed by a proposition (source of information), and do not explicate the speaker's assessment of the proposition verity.

V.A. Plungian (2000) represents an opposite point of view, which indicates the absence of grounds to declare evidentiality being a simple subspecies of epistemic modality the same as to consider evidentiality and epistemic modality as the non-related categories. According to the author, in the "detailed" systems the markers of the evidentiality semantics have virtually no modal load as opposed to binary systems, in which any indirect information proves to be less reliable.

We propose to combine the categories of evidentiality and epistemic modality within the category of epistemic status that takes into account such parameters as the source of information, based on which an utterance is formulated, as well as the measure of reliability of this information. It is therefore necessary to draw attention to the fact that in terms of the cognitive activity, all utterances can be divided into the epistemically objective and the epistemically subjective ones. It is the latter that meet the above-mentioned parameters. The plan of expressing this category in the German language may include a conjunctive of indirect speech, modal words, modal verbs, and the verb scheinen.

\section{Discussion}

\subsection{The concept of evidentiality}

Proceeding to study the interactions of the categories we are interested in, we should first note that certain studies widely discuss the question about the possibility of allocating one integrated category on the basis of two other 
categories - evidentiality and epistemic modality. However, until now the status of these categories remains controversial and requires a more detailed study. Each approach has both supporters and opponents.

To compare the category of evidentiality and epistemic status of utterance, we should definitely specify their semantic potential. When it comes to semantics of utterances with evidential value, it is worth mentioning the opinion expressed by N.A. Kozintseva (1994), for which it includes such parts as the frame (EV) and proposition (P): G reports that [X saw/believes/got know that] P, where G - speaker, X - subject of EV modus ("owner" of information). At the same time, information can be obtained due to: a) sensory perception, b) logical reasoning, c) messaging. The perceptual perception, in turn, is divided into visual observation, auditory observation, and observation based on common perceptions.

Linguistic literature also presents other, more fractional, classifications of information sources. Thus, for example, V.A. Plungian (2000) contrasts the "direct" information (situation observed by the speaker) with the "indirect" information (situation unobserved by the speaker). In addition to these sources, the "immediate" information (a possibility of the speaker's personal access to facts) and "intermediate" information (the absence of the speaker's personal access to facts) are analyzed. At the same time, the direct information is immediately related to the speaker, while the indirect information may be not only of personal, but also of intermediate nature. The further subdivision is associated with the allocation among the direct visual sources of information (an optical observation of situation), sensory sources of information (contemplation of situation with other senses), and "endophoric" sources of information (inner feelings of the speaker). With regard to indirect sources of information, they include inferentives (reasoning the situation by its results) and presumptives (reasoning the situation by logic considerations).

\subsection{The concept of epistemic modality}

Turning next to the term "epistemic" (from the Greek word "epistēme" - knowledge), we should note that it came into linguistics from logic, into which it was introduced due to expansion of the modality concept.

When interpreting the nature of epistemic modality, there are certain disagreements among linguists. Some researchers, influenced by the modal-logic inquiries, associate the epistemic modality with the concepts of possibility and necessity. In particular, F.R. Palmer $(1979,2001)$ presents such an approach in his works, for which a speaker expresses assessment of the proposition reliability by means of epistemic modality.

Other researchers attempt to define the epistemic modality through the concepts of probability and reliability/verity. Thus, T.A. Maisak and S.G. Tatevosov (2000) understand the category of epistemic modality as the one that associates with the explication of the speaker's point of view on the verity of a proposition, or, in other words, with the assessment of probability of that the situation takes place in the actual world. According to the authors, the semantic domain of the epistemic modality correlates with the scale, one of the extreme points of which indicates the probability of a situation equal to unity - the situation described exists in the actual world. While the other one counts in favor of probability of a situation equal to zero - the situation described does not exist in the actual world. The cases, when a speaker admits a possibility of both alternatives with varying degrees of probability, occupy the gap.

In some studies, the nature of epistemic modality is interpreted through the prism of possible worlds. Thus, M. Willer (2013) considers that a speaker uses utterances with semantics of epistemic modality to clarify a system of possible worlds.

According to the Finnish linguist Mustajoki A. (2006), the epistemic modality associates with semantic elements that indicate the speaker's attitude to the reliability of situation. At the same time, one of the options proposed to classify epistemic modality is the following scale: virtually absolute confidence (high degree of probability) - moderate confidence (medium degree of probability) - almost complete lack of confidence (low degree of probability).

Considering such types of modality as agent-oriented, speaker-oriented, epistemic, and subordinating ones, J. Bybee et al. (1994) associates the epistemic modality with the responsibility for the proposition reliability covering the values of possibility, probability, and inferential confidence, which form the scale of author's confidence in the reliability of proposition in the direction from low to high degree of feature intensity.

\subsection{The concept of epistemic status}

As seen from the above mentioned arguments of linguists, pertaining to the semantic parameter of an utterance, the category of evidentiality reflects the source of information, based on which an utterance is formulated, whereas the epistemic modality speaks in terms of concepts of reliability, probability, necessity, and possibility. In light of these judgments, it is hard to escape a conclusion that it is impossible to combine into one these categories due to the mismatch in the plan of their contents, and that it is legible to raise such a question in general. However, it would be naive to believe that the issue under discussion has an unambiguous solution. The essence of this problem consists in that the categories of evidentiality and epistemic modality have a significant zone of intersection mainly in terms of common means of expression, primarily the modal verbs and modal words in the Germanic languages. An utterance He must be at home, on the one hand, indicates a logical consideration of speaker, and on the other hand - a high degree of probability of the situation. In other words, in case of differences in the plans of contents of the categories of evidentiality and epistemic modality, we can observe the coincidence in the plans of expression thereof, in particular in the Germanic languages.

In order to overcome the differences of such nature, some works (Shakirova, 2009) develop a new approach to the categories under study within the category of epistemic status. 
The epistemic status takes into account two parameters of the situation, based on which an utterance is built - a source of information and a degree of the speaker's awareness, in other words, a degree of the information reliability. From the perspective of epistemic status, any utterance can be either objective or subjective. In contrast to the epistemic objectivity, when an utterance experiences redundancy of markers indicating the source of knowledge and its probability due to the absolute reliability of its content, an utterance associated with epistemic subjectivity takes into account both parameters of utterance. The utterances I hear a song; my heart hurts; Moscow is the capital of Russia; $2 \times 2=4$ are epistemically objective since the expression of any doubt regarding their reliability in the situations, that do not have a particular pragmatic sense, is impermissible.

Being marked with an element of opposition, a subjective epistemic status of utterance correlates with such phenomenon of objective reality, in relation to which not only the knowledge, but also a lack of knowledge or even a speaker's uncertainty as well as the clarification of the source of knowledge acquisition - "How do you know this?" or "How do I know this?" - are equally possible (L. Wittgenstein, 1969-1975). L. Wittgenstein studied the utterances of this kind, and later the Russian linguists M.A. Dmitrovskaya (1988), E.S. Yakovleva (1994), and others summarized them. These are the three types of knowledge, based on which an utterance is formulated. Firstly, this includes an immediate knowledge based on the sensory observation. An inferential knowledge obtained by logical reasoning occupies an intermediate position between knowledge and ignorance. Finally, the last third type of the knowledge under study is a "second-hand" knowledge acquired in the course of interpersonal communication. These types of knowledge do not always contribute to acquiring complete and reliable picture of the objective reality so they are characterized by a varying degree of reliability.

As we see, the concept of epistemic status of an utterance is wider than the concept of evidentiality and epistemic modality since the structure of its content includes not only the indication of the source of information (though in both cases one and the same types of information sources act as the study subject), but also the characteristics of the degree of reliability of the knowledge acquired therewith. We can assume that this difference should find its confirmation in the linguistic material. Therefore, let us proceed to the examination of linguistic means actualizing these values in the modern German language.

\subsection{Morphological means of expressing the category of epistemic status}

It is well known that many languages possess morphological means of expressing the semantics of evidentiality. A special non-obvious/retelling or paraphrasing mood pertains to the Turkic, Finno-Ugric, Samoyed, and other languages. It is noteworthy that a retelling mood is based on the forms of perfect tense, which later form an individual mood. This mood is used to denote an action, which was not witnessed by speaker and is an evidence of his uncertainty. We can consider the formation of a retelling mood as a consequence of the evolution of perfect forms. With regard to the modern German and other Germanic languages, we should note that until now the German perfect tense has not been unambiguously interpreted. However, there are no studies of perfect tense from the perspective of its participation in the category of evidentiality in Germanics.

Meanwhile, one cannot deny that in the modern German language the means of explicating semantics of evidentiality are functioning. Thus, the units of evidentiality expression may include German conjunctive mood functioning in indirect speech along with the indicative mood widely represented in many languages. Despite the fact that it still has not reached such a level when it can serve as an independent means of marking "second-hand" knowledge, the cases of conjunctive indirect speech in the form of independent sentences representing a "chain" that do not possess an introducing verb of speech are well represented in the texts of fictional prose and journalism. Here is an example: Indem Hanna zugab, den Bericht geschrieben zu haben, hatten die anderen Angeklagten leichtes Spiel. Hanna habe, wo nicht allein gehandelt, die anderen bedrängt, bedroht, gezwungen. Sie habe das Kommando an sich gerissen. Sie habe Feder und Wort geführt. Sie habe entschieden. (Once Hanna admitted having written the report, the other defendants had an easy game to play. When Hanna had not been acting alone, they claimed, she had pressured, threatened, and forced the others. She had seized command. She did the talking and the writing. She had made the decisions.)

Probably, this fact allowed B. Hansen (2007) to classify the indirect speech conjunctive to the evidentiality indicators. However, in indirect speech two forms of conjunctive mood are used - present and preterite, which are synonyms within the framework of paradigmatics. On the one hand, they refer to the units of morphological level; on the other hand, they have the same composition of semes, namely secondariness of knowledge, indirectness of reproduction, and detachment of speaker, on which the semes are overlapped indicating a temporal perspective of an utterance. However, on the syntagmatic level, the paradigmatic synonymy is broken since the reproducer through various conjunctive forms can mark different level of reliability of the foreign information. In general, the present conjunctive focuses on the expression of a greater degree of confidence in the other's utterance, while the preterite conjunctive, on the contrary, expresses a lesser degree. Conjunctive forms in indirect speech transmit different level of speaker's detachment depending on the degree of reliability of the information reproduced from the speaker's perspective. Therefore, we include indirect speech conjunctive to the indicators of the epistemic status category.

Functioning of the present and preterite forms of conjunctive in indirect speech is connected with the necessity of grading the level of reliability and speaker's detachment from the utterances of a third person. The concept of detachment is endowed with the feature of graduality, which leads to the functioning of two forms of conjunctive in the modern German language and likewise supports the use of conjunctive along with indicative in indirect speech. 
Choosing one of the conjunctive forms may be caused by the degree of reproducer's respect to the "owner" of information, his prior knowledge of the situation, which he compares with the reproducible facts. At discrepancy, he prefers to distance himself by using preterite conjunctive in indirect speech.

Let us draw our attention to the fact that language can be attributed to the dissipative structure or a self-organizing system, in other words, a system aimed at creating advanced structures. The term "dissipation" owes its introduction into scientific usage to the theory of open systems, to the study of a particular type of dynamic states, dissipative selforganizing structures associated with the spontaneous occurrence of "order out of disorder". The self-organization can be attributed to the possible way of language evolution. Therefore, in the German language the parallel functioning of the two moods in indirect speech can be adequately explained by the property of self-organization of the language structure.

\subsection{Lexical means of expressing the category of epistemic status}

Modal words refer to another means that explicates the source of the information received. E. Hentschel и P. M. Vogel (2009) following the Duden-Grammatik (2005) consider modal words only as indicators of the speaker's subjective opinion. However, as the observation of linguistic material shows, such modal words as augenscheinlich, bekanntlich, bestimmt, erwiesenermaßen, freilich, gewiss, keinesfalls, keineswegs, natürlich, offenkundig, selbstredend, selbstverständlich, sichtlich, tatsächlich, unbedingt, wahrhaftig, wirklich, zweifellos, zweifelsfrei, zweifelsohne correlate with the sensory perception of reality. Indicating the perceptive nature of the acquired knowledge, they mark a high degree of reliability of this knowledge.

To illustrate, let us consider an example from the novel "Perfume: The Story of a Murderer" by P. Süskind. By means of a modal word bestimmt, the categorical reliability of the information obtained through direct eye contact is transmitted. In this context, the channel of acquiring information mit eigenen Augen is specified along with the verb sehen. Only a witness of the situation can "see with his own eyes", therefore, it is possible to argue that in this case the highest level of reliability of the message is explicated: Grenouille fragte die Wache, welche Straße der Zweite Konsul genommen habe. Der Posten wies nach Norden. Nicht die Straße nach Cabris? Oder die andere, die südlich nach Auribeau und La Napoule führte? - Bestimmt nicht, sagte der Posten, er habe es mit eigenen Augen gesehen. (Grenouille asked the watch which road the second consul had taken. The guard pointed north. Not the road to Cabris? Or the other one, that went south toward Auribeau and La Napoule? Definitely not, said the guard, he had watched with his own eyes.).

Let us note that the verb scheinen functions in the modern German language, which explicates a poor quality knowledge acquired on the basis of sensory cognition of the reality. In the situation of incomplete awareness, speaker experiences difficulties in the perception that arises due to a "whim" of the channel of acquiring information, in other words, due to the interference caused by the indistinct contours of the perceived object because of the synoptic (poor visibility, poor audibility) factors or the human sensory systems defects (poor eyesight, impaired hearing, poor sensitivity, etc.) as well as due to the significant distance of the observed object from the speaker. Thus, in the following example, the words bei Nacht, im gleichen Licht des Mondes draw attention to poor visibility because of the darkness. These reasons make it possible to interpret the information on the situation, obtained by means of optical observation, as an incomplete one, and use the verb scheinen in the utterance: Und bei Nacht gar, im bleichen Licht des Mondes, schien sie in ihrer gottverlassenen Öde nicht mehr von dieser Welt zu sein. (And by night, by the bleaching light of the moon, it was such a godforsaken wilderness that it seemed not of this world.). The epistemic function of the verb scheinen consists in marking an incomplete, from the speaker's point of view, information, that emerges as a result of sensory perception of the objective reality.

Apart from the modal words that are appropriate in the situation of physical contact with the phenomenon described, the modern German language distinguishes modal words that mark the semantics of the subjective epistemic status of the utterances formulated as a result of intellectual activity: anscheinend, bestimmt, eventuell, höchstwahrscheinlich, kaum, möglicherweise, offenbar, offensichtlich, scheinbar, schwerlich, sicher, vermutlich, vielleicht, wahrscheinlich, wohl. Because these modal words indicate the inference nature of knowledge, they could be attributed to the evidential means. However, they are differentiated by the degree of confidence expressed by the speaker in the probability of inferential knowledge. Among the modal words, it is possible to distinguish those that convey a very high level of speaker's confidence in the probability of situation: höchstwahrscheinlich, bestimmt, offenbar, offensichtlich, sicher. The modal words eventuell, möglicherweise, vermutlich, vielleicht, wohl indicate the further decrease in the level of speaker's confidence in the probability of inferential knowledge. The modal words kaum, schwerlich, scheinbar explicate the lowest measure of the speaker's confidence.

\subsection{Lexical and grammatical means of expressing the category of epistemic status}

The modal verbs in secondary function mark the inferential knowledge. In "Deutsche Grammatik" (2010), the meaning of modal verbs is associated with the expression of assumption by speaker. The work "Compact grammar. German as a foreign language for quick search" states that the verbs dürfen and können possess a meaning of assumption, the verb müssen - of reasoning, the verb wollen - of doubt, while the verb sollen is used to transfer the meaning of hearing (Funk $\mathrm{H}$ et al, 2010). To my mind, along with the indication of an accomplished act of the mental operation of reasoning, the graduality of knowledge reliability is transmitted. As seen from the material studied, the modal verbs in the function of assumption are differentiated according to the expressed thereby degree of speaker's confidence in the probability of inferential knowledge. Thus, the verb müssen explicates a very high degree of speaker's confidence, which is substantiated in the accompanying communicative context. Such utterances can be transformed into complex 
sentences with the subordinate clauses of reason. For example, the verb müssen can introduce the presupposed clause of result due to the generalization of facts known to speaker from the living circumstances of the heroine from the novel "The Reader" by B. Schlink, whom he knows personally. The reason for the probable exhaustion of the heroine is her constant struggle. This can be confirmed by the transformation of an utterance into a complex sentence with subordinate clause of reason, in which the principal clause results from the reasons given in the subordinate clause: Sie mußte völlig erschöpft sein. Sie kämpfte nicht nur im Prozeß. Sie kämpfte immer und hatte immer gekämpft ... (B. Schlink) $\rightarrow$ Sie mußte völlig erschöpft sein, weil sie nicht nur im Prozeß kämpfte. Sie kämpfte immer und hatte immer gekämpft ... (She must have been completely exhausted. Her struggle was not limited to the trial. She was struggling, as she always had struggled $\rightarrow$ She must have been completely exhausted because her struggle was not limited to the trial. She was struggling, as she always had struggled.

The modal verbs können and mögen express a somewhat reduced level of the speaker's confidence. Moreover, the use of the verb mögen allows the speaker to point out simultaneously two possible variants for the development of situation, and by means of the verb können, he may consider an unlimited set of alternatives. The modal verb dürfen is characterized by a low frequency of use and expresses an uncertain assumption of the speaker.

The means of expressing the semantics of evidentiality may include the construction of a modal verb sollen in its secondary function, which implicitly refers to the "second-hand" knowledge, in other words, transmits someone else's message: Kein Mensch konnte es fassen, daß der windige, kleine, geduckte Mann dort oben am Fenster, dieses Würstchen, dieses armselige Häuflein, dieses Nichts, über zwei Dutzend Morde begangen haben sollte. (Not a soul could comprehend how this short, paltry, stoop-shouldered man there at the window-this mediocrity, this miserable nonentity, this cipher-could have committed more than two dozen murders (P. Süskind). However, in addition to specifying the secondary nature of the information, the reproducer's uncertainty in the reliability of information is transmitted.

\section{Conclusion}

So, we could consider the lexical and grammatical units listed as a means of actualizing the semantics of evidentiality and epistemic modality. However, on the one hand in addition to marking the source of knowledge, on the other hand they transmit a different level of its reliability. Often, the units that in different ways explicate the reliability of knowledge, based on which an utterance is formulated, function within the same linguistic level. Therefore, on the modern German language material we can speak primarily about the epistemic status of an utterance. The epistemically objective utterances do not provide information on the source of knowledge, by which they are supported, as well as on the level of their reliability as opposed to the utterances of the status of epistemic subjectivity. In the latter case, the utterances are based on the direct sensory perception, however subject to spatial and temporal detachment of the object of observation, inferential or "second-hand" knowledge. In this case, the utterance marks a different degree of implicit or explicit reliability. It is probably possible to distinguish a functional-semantic category of epistemic status, the plan of content of which is associated with the speaker's subjective assessment of the reliability of utterance, formulated as a result of its sensory or intellectual activity, as well as of the "second-hand" knowledge. The present work examines the main methods of explicating this category in the German language. The aim of further studies could be a complete inventory of the plan of expressing this category in the German language as well as the study of the epistemic status category on the material of other languages.

\section{References}

Burkova, S.I. (2004). Evidentiality and epistemic modality in German language: A study on the theory of grammar. Issue 3. Irrealis mood and irreality. Moscow, M. Gnozis.

Zaliznyak, Anna A. (2006). The ambiguity of language and methods of its presentation. Moscow, M. Languages of Slavic Culture.

Dmitrovskaya, M.A. (1988). Knowledge and reliability: Pragmatics and problems of intensionality. - Moscow, M. Academy Sciences of the USSR, Institute of Linguistics.

Khrakovsky, V.S. (2007). Evidentiality, epistemic modality, (ad)mirativity. In Evidentiality in the languages of Europe and Asia: Collection of articles of the memory of Natalia Andreevna Kozintseva. V.S. Khrakovsky (ed.). SPb: Nauka, 2007. PP. 600-629.

Kozintseva, N.A. (2000). On the question of attestation category in Russian language: An indirect source of information: Problems of functional grammar. Categories of morphology and syntax in utterance. St. Petersburg: SPb. Nauka.

Kozintseva, N.A. (1994). Category of evidentiality (the problem of typological analysis). Questions of linguistics. No. 3.

Lyons, J. (2003). Linguistic semantics: Introduction. Moscow: Languages of Slavic Culture.

Maisak, T.A., Tatevosov, S.G. (2000). Speaker's space in categories of grammar or What one cannot say about oneself. Questions of linguistics, 5.

Mustajoki, A. (2006). The theory of functional syntax: from semantic structures to linguistic tools. Moscow: Languages of Slavic Culture. 
Plungian, V.A. (2000). General morphology: Introduction to the problem. Moscow: Editorial URSS.

Hansen, B. (2007). Evidentiality in German. Evidentiality in the languages of Europe and Asia: A Collection of articles in memory of Natalia Andreevna Kozintseva. Edited by V.S. Hrakovsky. St. Petersburg: Nauka.

Shakirova, R.D. (2009). The concept of epistemic status of utterance and means of its actualization in the modern German language. Philological sciences, 2.

Shatunovskii, I.B. (1996). Semantics of assumption and non-referential words (meaning, communicative perspective, pragmatics). Moscow: School "Russian Culture Languages".

Jacobson, R.O. (1972). Shifters, verbal categories and the Russian verb: Principles of typological analysis of languages of different system. Moscow: Nauka.

Yakovleva, E.S. (1994). Fragments of the Russian linguistic picture of the world (models of space, time and perception). Moscow: Gnozis.

Bybee, J., Perkins, R. \& Pagliuca W. (1994). The Evolution of Grammar: Tense, Aspect, and Modality in the Languages of the World. Chicago, London: The University of Chicago Press.

Hentschel, E. (ed.) (2010). Deutsche Grammatik [German Grammar]. Berlin, New York: Walter de Gruyter GmbH \& Co. KG.

Funk, H., Koenig, V., Rohrman, L. (2010). Kompaktgrammatik. Deutsch als Fremdsprache zum schnellen Nachschlagen. Cornelsen.

Hentschel, E., Vogel, P.M. (2009). Deutsche Morphologie [German Morpholofy]. Berlin. Walter de Gruyter GmbH \& Co. KG.

Kuhn, T.S. (1962). The Structure of Scientific Revolutions. Chicago.

Malcolm, N. (1977) Moore and Wittgenstein on the Sense of 'I Know. Thought and. Knowledge. Ithaca \& London: Cornell University Press, 170-198.

Moore G.E. (1959). A defence of common sense. Philosophical papers. London: George Allen \& Unwin LTD New York: The Macmillan company.

Moore G.E. (1959). Proof of an external world. Philosophical papers. London: George Allen \& Unwin LTD New York: The Macmillan company.

Palmer, F.R. (1979). Modality and the English Modals. London, New York: Longman.

Palmer, F.R. (2001) Mood and Modality. 2nd edition. Cambridge: Cambridge University Press.

Willer, M. (2013). Dynamics of Epistemic Modality Philosophical Review 122(1).

Wittgenstein, L. (1969-1975). On Certainty (Uber Gewissheit). ed. G.E.M. Anscombe and G.H. von Wright. Oxford. 